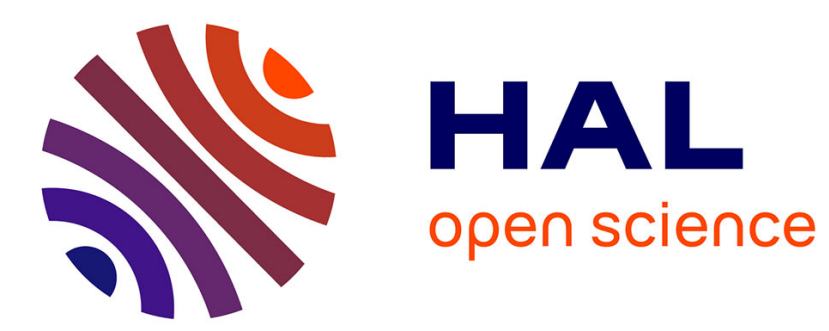

\title{
ATOM-PROBE STUDY OF G.P. ZONES IN Ti-Cu ALLOYS
}

L. Hadjadj, A. Menand, D. Blavette

\section{To cite this version:}

L. Hadjadj, A. Menand, D. Blavette. ATOM-PROBE STUDY OF G.P. ZONES IN Ti-Cu ALLOYS. Journal de Physique Colloques, 1986, 47 (C7), pp.C7-281-C7-286. 10.1051/jphyscol:1986748 . jpa00225942

\section{HAL Id: jpa-00225942 https://hal.science/jpa-00225942}

Submitted on 1 Jan 1986

HAL is a multi-disciplinary open access archive for the deposit and dissemination of scientific research documents, whether they are published or not. The documents may come from teaching and research institutions in France or abroad, or from public or private research centers.
L'archive ouverte pluridisciplinaire HAL, est destinée au dépôt et à la diffusion de documents scientifiques de niveau recherche, publiés ou non, émanant des établissements d'enseignement et de recherche français ou étrangers, des laboratoires publics ou privés. 


\title{
ATOM-PROBE STUDY OF G.P. ZONES IN Ti-Cu ALLOYS
}

\author{
L. HADJADJ, A. MENAND and D. BLAVETTE \\ Laboratoire de Microscopie Ionique, UA 808 CNRS, UER SCiences \\ de Rouen, BP 67, F-76130 Mont-Saint-Aignan, France
}

\begin{abstract}
Fésume - Nous avons etudie les zones G.F. dans un alliage Ti-2.3at\% Cu a I'aide d'une sonde atomique. Les analyses ont revelé une structure multicouches de ces zanes avec une alterrance possible de plans riches en cuivre et de plans riches en titane. La composition moyerre de ces plaquettes est comprise entre $20 \%$ et $40 \%$.

Abstract - G.F. zones in a Ti-2.3at\% Cu alloy were investigated on an atomic scale by means of aton probe. Aralyses revealed a multi-layer structure with a poseible alternation of copper rich planes with titanium rich planes. The copper average concentration of the platelets was found to be in a range of $20 \%$ to $40 \%$
\end{abstract}

\section{I - INTRODUETION}

In spite of some difficulties in tip preparation, and although tip failures are very common under the field stress, A.F. studies of high content titaniua base alloys are now performable /1/.

The particuliarity of titanium-copper alloys is that age-hardening is available by precipitation of copper enriched zones in the $\alpha$ phase $/ 2 /$. Better mechanical properties than those obtained with pure titanium are therefore available with such materials $13 /$.

The purpose of this study is to get more informations about the structure and the composition of G.F. zones in titanium-copper alloys.

\section{I - EXFEFIMENTAL}

The alloys $\mathrm{Ti}-3 w t \% \mathrm{Cu}$ were supplied by the Office National d'Etudes et de Fecherches Aerospatiales (O.N.E.F.A.). They were prepared by using arc-melting technique. They were solution treated 1 hour at $800^{\circ} \mathrm{C}, 1$ hour air cooled and then aged 28 days at $400^{\circ} \mathrm{C}$. This treatment leads to obviously visible precipitates forming coherent platelets on (1011) planes of the alpha matrix/4/ Figure 1.

The field ion microscopy specimens were prepared by anodic electropolisting in a solution of $6 \%$ perchloric acid $34 \% n$-butyl alcohol and $60 \%$ methanol. In order to avoud passivation phenomena it has been necessary to product a circulation of the solution obtained by means of a peristaltic pump. Ari electropolishing cell has been specially designed to that effect.

The atom probe used in this study is a conventional one. The instrumerit details and performances are described elsewhere /5/. Feliable data were obtained by using a pulse fraction of $20 \%$ of the DC voltage, an a tip temperature 1 ying between $40 k$ and 
80 K. Analyses were carried out in a vacuum of $10^{-9}$ Torr. FlM observations were performed at $20 \mathrm{k}$. The figure 2 shows a FIM micrograph of a Ti-3wt\%Cu specimen obtained with neon as imaging gas. A low index pole is clearly visible. The titanium is observed in the mass spectra as doubly charged ions while the copper is detected as doubly and for a smaller part as singly charged ions.

\section{III - RESULTS AND DISCUSSION}

\section{Composition}

The composition averaged over all the analyses is $1.40 \pm 0.05 a t \%$ of copper. This result is in good agreement with the solubility limit of copper in the alpha phase at the eutectoid point given in the literature as $1.6 a t \% / 6 /, 1.25 a t \% / 7 /$ or 1.4at\% 18\%. The excess of copper in $\mathrm{Ti}-3 \mathrm{wt} \% \mathrm{Cu} \mathrm{i}$. E Ti-2.3at\% Cu leads to a grain boundary precipitation of a $\mathrm{Ti}_{2} \mathrm{Cu}$ phase $/ 3 /$. Eeczuse this phase is not homogeneously dispersed we only encounted two precipitates of this kind during our investigations.

\section{Depth of analysis}

One major problem in A.F. data analysis is the determination of the depth of analymis. This is of particular significance when the studied objects are $5 \mathrm{mall}$ platelets of unkrown thickness.

When the ring counting technique or even layer by layer analysis are not usable (poor image quality ...), the following general relevant expression of the analysis depth p can be used /8/:

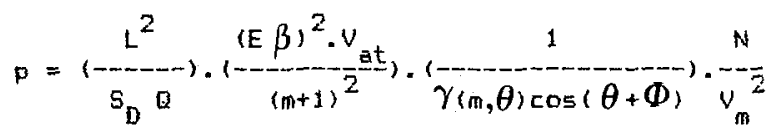

where $N$ is the number of detected ions and $V_{m}$ the average evaporation voltage.

The first term of this expression depends: upon the apparatus itself (detector efficiency $Q$, flying path $L$, detector area $S_{D}$ ).

The second factor is related to the material parameters satomic volume Vat' evaporation field $E$ and geometrical factor $\beta$, projection point $m$ ).

The third term depends upon the site of analysis langle $\theta$ between the tip axis and the normal to the investigated pole (hil), angle $\Phi$ between the tip axis and the detector direction).

Therefore two fossibilities exist to get a practical formula:

$$
p=t \cdot N / v_{m}^{2}
$$

The first is to perform a layer by layer analysis on a known pole located near the tip axis where $\gamma(m, \theta) \cos (\theta+\Phi)=1$ and to deduce $k$ from the number of detected atoms per plane.

The second is to estimate from the results obtained with an other material inickel in our case) where this $k$ parameter is known in the same atom probe contiguration:

$$
k_{T i}=k_{N i} \cdot \frac{(E \beta)_{T i}^{2} \cdot V_{\text {at }} \cdot \frac{1}{2}}{(E \beta)_{N i}^{2} \cdot V_{a t N i}}
$$

The first method supposes the possibility to index the different poles. In fact this is not often the case with titanium because of the poor contrast of FIM images. However it is possible to make some assumptions between four or five low index poles and to compare the results for $k$ to the one obtained by the second method. 
Fortunately we succeed to traverse G.F. zones during layer by layer analyses, this allows to clearly recognize these plaries as the habit planes (10î1). Therefor ${ }_{2}$ this gives us a more reliable determination of $k$. Finally we foung $k=17 \pm 1.5 \mathrm{AkV}^{2}$ while the result obtained by the second method was $16.5 \pm 2.5 \mathrm{AkV}^{2}$.

\section{Analysis of platelets sideway crossed}

A typical profile is given in figure 3. It surely indicates that a G.F. zone has been crossed but is not very informative as regards the real structure and composition of the platelet. However some indications can be drawn from such a profile.

If $p$ is the crossing length through the E.F. zone (figure 4 ), $\alpha$ the angle between the platelet and the analysis cylinder axis, n.d(hkl) the thickness of the platelet and $D$ the diameter of the analysis cylinder, one can write:

$$
\operatorname{tg} \alpha=D /\{p-n \cdot d / \sin \alpha\}
$$

which leadsto:

$$
\sin \alpha=\left(n \cdot d \cdot p+D \cdot\left(p^{2}+D^{2}-n^{2} \cdot d^{2}\right)^{1 / 2}\right) /\left(p^{2}+D^{2}\right)
$$

it is then possible to calculate each $\alpha$ value corresponding to the various values of $n$.

Afterwards the possible compositions of the G.F. zone can be derived. Since the elliptic surface of the platelet intercepted by the analysis cylinder is: $S=D^{2} /(4 \cdot \sin \alpha)$ the expected number of collected atoms for a platelet whose thickness is n.d is:

$$
N_{p}=0 . D^{2} \cdot n . d / 4 . V_{a t} \cdot \sin \alpha
$$

with $Q$ the detector efficiency.

Then the platelet composition is :

$$
C_{p}=N_{C u} / N_{p}
$$

where $\mathrm{N}_{\mathrm{Cu}}$ is the observed number of copper atoms.

Obviously since $N_{p}$ depends on the $\alpha$ angle, it exists a couple $c_{p}(n), \alpha(n)$ for
value of $n$. each value of $n$.

The 1 ast information being used is the maximum concentration observed $c$ in the central part of the profile. This concentration can al so be derived from $n$ and $\alpha$ :

$$
c_{c}(n)=c_{p}(n) \cdot \sum_{i=1}^{n} 1_{i}, \sum_{i=1}^{n_{T}} 1_{i}
$$

where $1_{1}$ are the intercepted length of (hk) planes (figure 4), $n$ the number of (hkl) planes in the platelet, ${ }^{n} T$ the number of (hkl) planes intercepted by the analysis area.

Therefore a comparison between the calculated $c_{c}(n)$ and the observed value $C_{0}$ can be done.

The table 1 gives the results for $\underset{r}{\alpha}, \mathrm{C}_{n}$ and $\mathrm{C}_{r}$ for the zone of figure $s$. 
Table 1

$\begin{array}{lccc}\pi & \alpha^{*} & c_{p} & c_{c} \\ 1 & 46 & 1.10 & 0.25 \\ 2 & 51 & 0.60 & 0.30 \\ 3 & 56 & 0.43 & 0.38 \\ 4 & 62 & 0.34 & 0.34 \\ 5 & 67 & 0.28 & 0.28\end{array}$

These results indicate that the observed profile could have been obtained either with a platelet of one pure copper layer erossed at $46^{\circ}$ by the analysis cylinder (obviously 1.1 has to be taken as 1), or with platelets of 2 , 5,4 or 5 layers with decreasing concentrations traversed with the indicated angles.

But the observed composition at the central part of the zone:

$C_{0}=16 \mathrm{Cu}$ atoms $/ 43 \mathrm{Cu}+\mathrm{Ti}$ atoms $=37 \%$

indicates that a 3 or 4 layers structure seems to be more litely.

Fiqure 5 gives a different profile for a platelet crossed more perpendiculary. The slope of this profile indicates that the platelet is not composed of a single plane but at least of 3 or 4 planes and suggests as alterned structure Cu rich plane - Ti rich plane(s) - Cu rich plane.

The different profiles we observed were all similar to one or the other previous ones.

\section{Layer by layer analysis}

Since the random analysis of G.F. zones seems to indicate a complex structure of 3 or 4 layers, it was therefore interesting to attempt a 1 ayer by 1 ayer analyeis as Hashizume and Sakurai did $/ 9 /$ for Al-Cu. We tried this on different poles with the hope that one of them will be the (1011) habit plane.

Figures ba and bo show the copper cumulative plots obtained for two different layer by layer analyses. The flux curves vertically drawn allow to marl: the different layers.

The first platelet (figure ba) has a thickness of four layers with a similar alterned structure as suggested previously: one copper rich layer, two titanium rich layers, one copper rich layer. Of course we have to take in account the possible statistical deviations because of the very small number of collected atoms in such arialyses.

The second profile obtained with a somewhat larger detection area exhibits a similar multi-layer structure with four layers. The average composition is found to be $28 \% \pm 10 \%$ of copper.

\section{IV - CONCLUSION}

We performed analyses on a Ti-Bwt\%Cu alloy containing copper enriched. 6.F. zones. The value of 1.4 at of copper obtained over all the experiments in good agreement with the solubility limit of copper in the alpha matrix gives us confidence about the data reliability.

The G.P. zones randomly crossed or during layer by layer analysis are multilayer platelets with a possible number of 3 to 5 layers. Some results suggest an alterned structure. copper rich -titanium rich layers. The average platelet compositions are ranged from $20 \%$ to $40 \%$. 


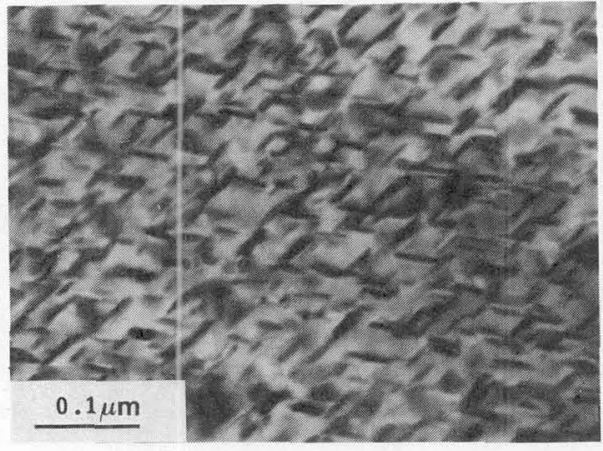

Fig 1 : Bright Field Electron micrograph of a $\mathrm{Ti} 3 \mathrm{Cu}$ alloy aged 28 days at $400^{\circ} \mathrm{C}$ (from VASSEL $/ 4 /$ )

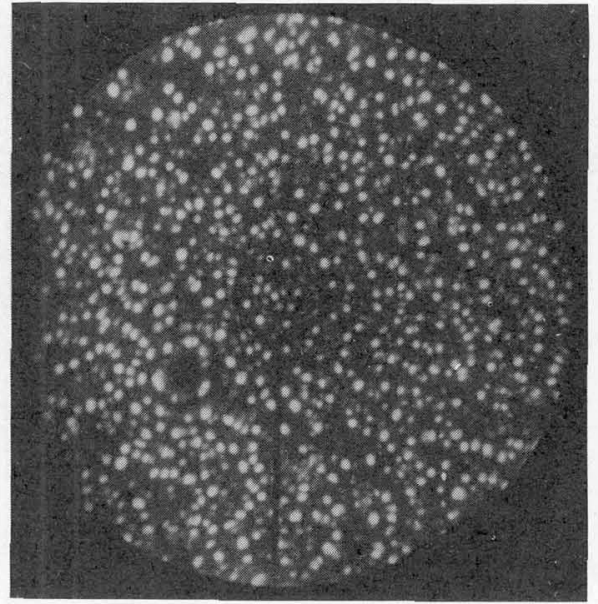

Fig 2 : FIM Micrograph of a $\mathrm{Ti}$ 3Cu Specimen

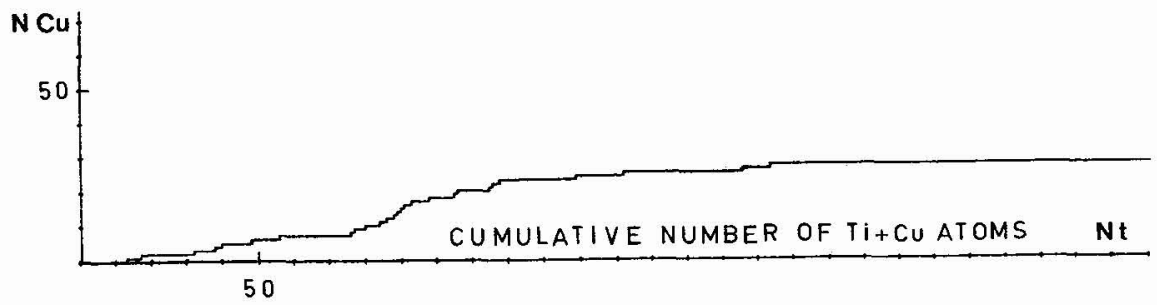

Fig 3 : Integral profile of Cu showing the crossing of a G.F. zone

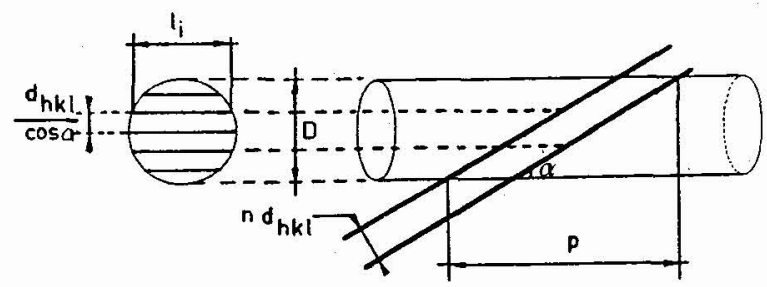

Fig 4 : Schematic of the crossing of a platelet by the analysis cylinder 
Acknowledgments

We wish to thank Dr. Vassel from O.N.E.R.A. for fruitfull discussions.

\section{REFERENCES}

11/ A. Menand, S. Chambreland, C. Martin, J. de Fhys. 47, C2-197-(1986)

12/ J.C. Williams, R. Taggart, Met. Trans.,2, 1139 (1971)

/3/ F.A. Blenkinshop, R.E. Goosey, "Science Technology and application of titanium", Fergamon Frese, 783 (1970)

14/ A. Vassel, 5th International Symposium on Titanium, Münick (1983)

/5/ C. Martin, D. Blavette, J.M Sarrau, Rev. Phys. Appl., 19, 27 (1984)

/6/ A. Joukainen, N.J. Grant, C.F. Floe, J. Metals, 4, 766 (1952)

17/ A.D. Me Quillan, 3. Inst. Metals, 79, 73 (1951)

/8/ D. Blavette, J.M. Sarrau, A. Bostel, J. Gallot, Fev. Phys. Appl.17, 435 (1982)

/9/ T. Hashizume, K.Hono, Y. Hasegawa, K. Hirano, T. Sakurai, J. de Fhys. 47, C2-171 (1986)

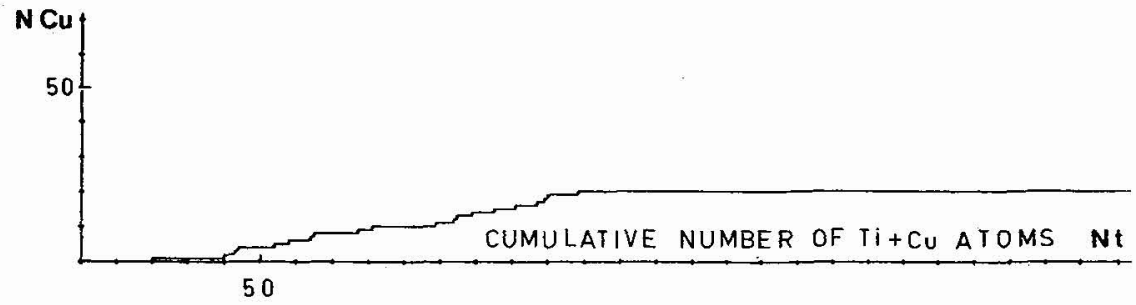

Fig 5 : Integral profile of Cu showing the crossing of a G.P. zone

\section{Fig $b a$ and $b$ Integral protiles of $\mathrm{Cu}$ and $\mathrm{Ti}$ in layer by layer analysis of two G.F. zones, with the corresponding flux curves $N_{\text {pulse }}$ versus $\mathrm{N}_{t}\left(\mathrm{~T}_{\mathrm{i}}+\mathrm{C} U\right)$.}

(a)

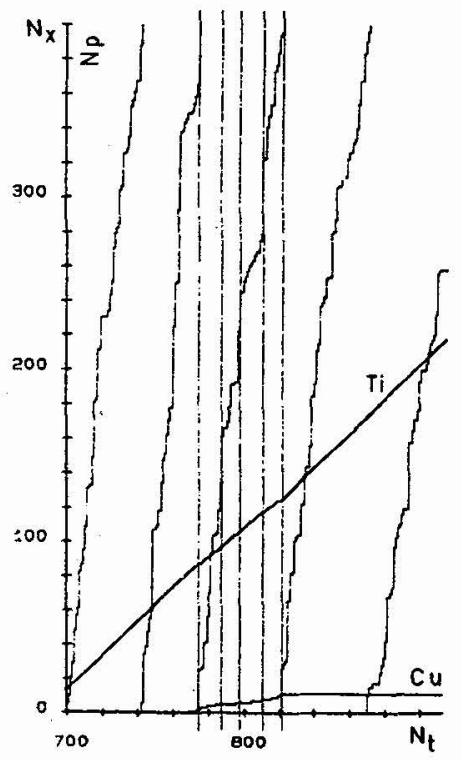

(b)

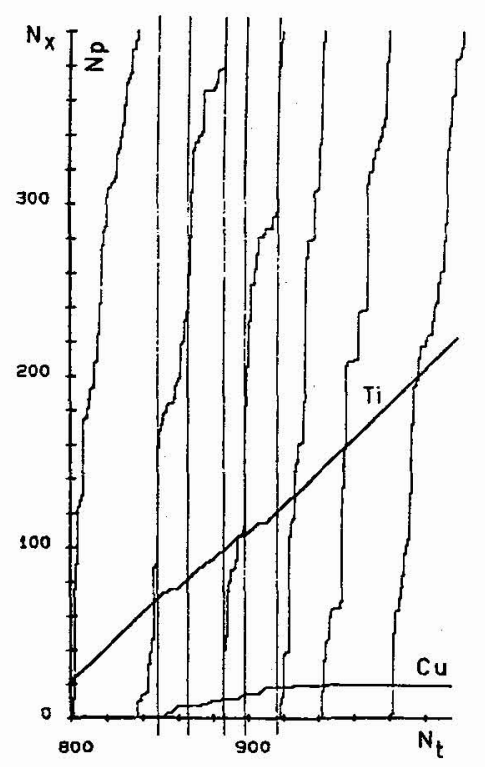

